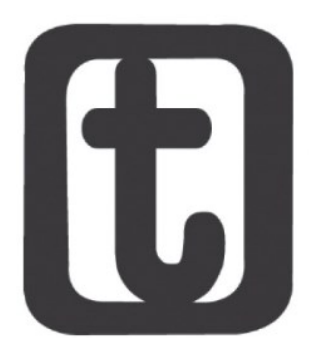

\title{
IDEOLOGIA E SERVIÇO SOCIAL: UM DEBATE NECESSÁRIO PARA A INTERVENÇÃO PROFISSIONAL
}

\author{
Ideology and social service: a debate necessary for professional intervention
}

\author{
Leandro Nunes* \\ Aline Aparecida Justino**
}

\begin{abstract}
RESUMO
Este artigo tem por objetivo realizar análises preliminares no que se refere o complexo da ideologia em sua perspectiva histórica e categorial. Para sustentar nosso objetivo, nos apoiaremos na tese de GyörgyLukács, o autor compreende que ideologia vai para além de "falsa consciência", ela possui uma função específica explicitar e dirimir as relações de homens e mulheres na sociedade de classes. Realizado este debate introdutório, nosso objetivo se tratara de compreender qual a função que este complexo categorial exerce na intervenção profissional do/da assistente social,bem como, defender a necessidade de apreendemos a ideologia enquanto um complexo que explicita e regula as subjetividades e objetividades de homens e mulheres sob as relações sociais capitalistas, debate este tão necessário para a sustentação do Projeto ÉticoPolítico, Código de Ética Profissional, Lei que Regulamenta a Profissão e Diretrizes Curriculares. Visto que, nos encontramos diante do contexto de agudização das contradições entre capital e trabalho, e reafirmar, a ideologia enquanto função social, não é senão, eminentemente necessário para que o/a profissional "dê" uma direção crítica e propositiva à sua intervenção com vistas a universalização dos direitos sociais e emancipação humana.
\end{abstract}

\section{PALAVRAS CHAVES}

Ideologia. Função social. Serviço social.

\section{ABSTRACT}

This article aims to carry out preliminary analyses regarding the complex of ideology in historical perspective and your protection. To sustain our goal, we support the thesis of György Lukács, the author understands that goes beyond ideology of "false consciousness", she has a specific function clarify and resolve the relationships of men and women in society. Held this introductory debate, our goal was to understand if what function this categorial complex exercises in professional intervention of the social worker, as well as defend the need of impounded the ideology as a complex that explicit and regulates the subjectivities and objetividades of men and women under the capitalist social relations, debate this so necessary for support of the Ethical-political Project, code of professional ethics, Law regulating the profession and Curriculum Guidelines.As we face the context of exacerbation of contradictions between capital and labor, and reaffirm the ideology as social function, is not otherwise eminently necessary so that s/he "give" a critical and purposeful direction to your intervention with a view to universalizing social rights and human emancipation.

\footnotetext{
* Assistente Social. Mestre em Serviço Social. Doutorando em Serviço Social pelo Programa de Pós-Graduação em Serviço Social da Universidade Federal de Santa Catarina. (UFSC, Florianopólis, Brasil). R. Eng. Agronômico Andrei Cristian Ferreira, s/n, Trindade, Florianópolis (SC), CEP.: 88040-900. E-mail: <leccinunes23@hotmail.com>.

** Assistente Social. Mestra em Serviço Social pelo Programa de Pós-Graduação em Serviço Social da Universidade Federal de Santa Catarina. (UFSC, Florianopólis, Brasil). R. Eng. Agronômico Andrei Cristian Ferreira, s/n, Trindade, Florianópolis (SC), CEP.: 88040-900. E-mail: <alinejustino@gmail.com>.
}

DOI 10.22422/temporalis.2018v18n36p274-289 


\section{KEYWORDS}

Ideology. Social role. Social work.

Submetido em: 30/9/2018.

Aceito em: 20/12/2018.

\section{INTRODUÇÃO}

Na atualidade, seja via senso comum, seja em razão do avanço do pensamento conservador, pós-modernoconvencionou-se reduzir a categoria ideologia a um mero conjunto de ideias, a falsa consciência, no entanto, a nosso entendimento, não podemos reduzir uma categoria histórica e dialética a uma ideia passageira e/oua uma abstração do real, sendo assim, é necessário que a compreendamos enquanto um complexo categorial da vida em sociedade que junto ao trabalho, reprodução e estranhamentos compõe a historicidade de homens e mulheres em sua práxis social, ou seja, a ideologia assume uma função específica: explicar e dirimir as ações humano-sensíveis. Neste sentido, é necessário que busquemos sua análise e apreensão a partir da teoria social crítica. Para tal, retornaremos aos escritos de Marx e Engels (2007) e seus contemporâneos. Acreditamos que em virtude dos distintos enfoques e concepções que tem circulado em relação a este complexo categorial (nas mais distintas áreas de conhecimento), que se justifique a relevância das análises contidas neste artigo.

No primeiro momento, nosso texto tratará de analisar o complexo da ideologia e sua perspectiva categorial. O termo "ideologia" surge no trânsito do século XVIII ao XIX, com o filósofo francês Antoine Destutt de Tracy, para o francês ideologia se referia a ciência das ideias e se enquadrava em um ramo da zoologia que tinha por objetivo estudar o animal humano. Marx e Engels, grandes filósofos materialistas do século XIX, no ano de 1844 terminam uma grande obra que vem a influenciar o pensamento ocidental, a Ideologia Alemã, a nosso entendimento, a obra que acabamos de citar vai muito para além das críticas a Bruno Bauer, ali marca a superação de Marx e Engels com o materialismo mecanicista de Ludwig Feuerbach, a superação da qual estamos falando se atesta com radicalidade na 11 Tese sobre Feuerbach, na qual Marx e Engels combatem a visão abstrata de mundo, afirmando que, "Os filósofos apenas interpretam o mundo de diferentes maneiras; porém, o que importa é transformá-lo” (MARX; ENGELS, 2007, p. 539). Sustentado nesta grande obra, Konder (2002), destaca que, no decorrer da história homens e mulheres se portaram e se relacionaram de distintas formas seja com a natureza, seja com outros de sua espécie, a esta peculiaridade de se relacionar uns com os outros, atentos ao contexto histórico em que se vivia, que constitui o complexo da ideologia, uma vez que, de acordo com Lukács, o ser social em seu complexo de mediações é demiurgo de sua própria história. Dito isto, não concordamos com a tese de que ideologia é apenas "falsa consciência", a nosso entendimento, sustentado pelos escritos de Marx, Engels, Lukács, Konder, Lessa, entre outros, a ideologia possui uma função específica na sociedade de classes antagônicas, explicitar e intervir nas relações sociais.

Na sequência nossa exposição, trará breves análises no que se refere a importância de se apreender a ideologia enquanto função social e sua referida importância na intervenção profissional e produção de conhecimento no Serviço Social. É importante destacar, desde o início que não estamos partindo do princípio de que o Serviço Social é ideologia, como afirma Costa (1999). Partimos do pressuposto que enquanto força de trabalho assalariada, a/o assistente social em suas mais variadas formas de intervenção profissional, pode sim vir 
a contribuir na consciência de seus sujeitos demandatários, em sua busca pela emancipação humana, acesso aos direitos, etc. Diante deste contexto, assumir essa posição ideo-política da ação profissional é a possibilidade de uma intervenção profissional que vá para além do acesso aos direitos. Há uma tarefa coletiva a cumprirmos enquanto profissionais e enquanto sujeitos históricos, que é a de pensarmos junto aos homens e mulheres que compõe a sociedade de classes, possibilidades para nossa emancipação humana. Para expor nossas análises, nos guiaremos nos estudos de autores e autoras do interior do Serviço Social que se dedicaram ao estudo do complexo da ideologia, que são eles; Marilda lamamoto, José Paulo Netto, Marcelo Braz, Gilmaísa Macedo da Costa, Vicente de Paula Faleiros, Laura Tavares, entre outros.

\title{
A IDEOLOGIA EM SUA PERSPECTIVA CATEGORIAL
}

De acordo com Eagleton (1997), o termo logia deriva do estudo ou ciência de um determinado fenômeno, mas, o autor nos apresenta um importante alerta, ao longo dos tempos resultado de um profundo processo de inversão das análises na produção de conhecimento os vocábulos ou categorias terminadas em logia tem se preocupado mais em estudar o fenômeno do que realizar uma análise da essência, da realidade da qual esta se estudando'. Para ilustrar sua tese, o autor cita o exemplo da metodologia, de acordo com o autor costumeiramente nas pesquisas tem se preocupado mais em explicitar o que vem a ser o método em Marx do que aplicar a teoria social marxista em suas interpretações e formulações teórico-metodológicas. E com a palavra ideologia o processo foi o mesmo, nas palavras de Eagleton (1997):

\begin{abstract}
Não levou muito tempo para que tal inversão ocorresse também com a palavra ideologia. 'Ideologia' originalmente significava o estudo científico das idéias humanas, mas não demorou para que o objeto ultrapassasse a abordagem, e a palavra rapidamente passou a referir-se aos próprios sistemas de idéias. Um ideólogo, então, significava não tanto alguém que analisava idéias, mas alguém que as expunha. [...]. A 'ideologia' era uma tentativa de restituir as idéias a seu domínio, enquanto produtos de certas leis mentais e fisiológicas. Porém, para levar a cabo esse projeto, era necessário conceder enorme atenção ao reino da consciência humana; é compreensível, portanto — embora irônico —, que esses teóricos tenham começado a acreditar que as idéias eram a única coisa que existia (EAGLETON, 1997, p. 65).
\end{abstract}

Dando sequência a seu texto,Eagleton nos diz que o termo 'ideologia' tem seu bojo na passagem do século XVIII ao XIX, com o filósofo francês Antoine Destutt de Tracy, que de acordo com o francês é a ciências das ideias, para de Tracy a ideologia é uma parte do ramo da Zoologia que se destinava ao estudo do animal humano. Ainda de acordo com Eagleton, de Tracy era de linhagem nobrearistocrata que renegou sua família ao se alistar e lutar junto aos representantes da burguesia na Revolução Francesa, Tracy desta forma se tornou "[...] um caso clássico da transição gramsciana do intelectual 'tradicional' para o ‘orgânico”' (EAGLETON, 1997, p. 67-68), e revela que:

A noção de ideologia nasceu, portanto em condições inteiramente ideológicas: a ideologia pertencia a uma política racional, contrária à barbárie irracionalista do Terror. Se os homens e mulheres deviam realmente governar a si próprios, então

\footnotetext{
${ }^{1}$ Suas análises estão se referindo ao contexto europeu (britânico em especial), no entanto, as análises do autor muito expressam a realidade da produção do conhecimento no Brasil, nas mais distintas áreas.
} 
era preciso, antes de tudo, esmiuçar pacientemente as leis de sua natureza. Para isso era necessário, afirmava De Tracy, 'um Newton da ciência do pensamento', e ele próprio era um óbvio candidato ao posto. Uma vez que toda ciência repousa em idéias, a ideologia desalojaria a teologia como soberana de todas elas, garantindo-lhes unidade. Reconstruiria completamente a política, a economia e a ética, partindo dos processos mais simples de sensação até as regiões mais sublimes do espírito. A propriedade privada, por exemplo, baseia-se em uma distinção entre o 'seu' e o 'meu', que se pode remontar, por sua vez, a uma oposição perceptiva fundamental entre 'você' e 'eu' (EAGETON, 1997, p. 68).

Tem-se a Ideologia Alemã como uma das principaisobrasem que Marx e Engels se dedicam ao estudo da ideologia, neste grande texto terminado em 1844 mas só editado pela primeira vez em 1933, Marx e Engels, não se limitam a realizar uma crítica a filosofia alemã de Bauer, Stirner e Feuerbach, a nosso entendimento, é nesta obra que Marx e Engels apresentam sua concepção de materialismo histórico ao superar o materialismo mecanicista de Feuerbach, na qual, de acordo com os filósofos o erro de Feuerbach está em apreender a realidade, o sensível enquanto um objeto, ou seja, para Marx e Engels a base de seu materialismo está na produção e reprodução da vida de homens e mulheres, a atividade humano-sensível sob circunstâncias historicamente dadas, a crítica dos filósofos a Feuerbach tem sua máxima expressão na $11^{\text {a }}$ tese, na qual, combatem a apreensão abstrata de mundofeurbachina e destacam que, "Os filósofos apenas interpretam o mundo de diferentes maneiras; porém, o que importa é transformá-lo" (MARX; ENGELS, 2007, p. 539). Konder, ao referenciar esta obra explicita que o objetivo de Marx e Engels era tecer suas críticas "[...] às distorções ideológicas da tradição idealista subjetivista, que supervalorizava o poder das representações" (KONDER, 2002, p. 39). No prosseguimento de suas análises, Konder (2002, p. 40), destaca que, a ideologia para Marx e Engels "[...] era a expressão da incapacidade de cotejar as ideias como o uso histórico delas, com a sua inserção prática no movimento da sociedade". Voltando aEagleton (1997), o surgimento do complexo da ideologia não "é um mero capítulo na história das idéias", este complexo esta intrinsecamente relacionado a luta de classe e a possibilidade da emancipação humana, aqui a nosso entendimento se repousa a apreensão deste complexo categorial enquanto função social que "explica" e intervém nas relações em sociedade. Ao se referir ao complexo da ideologia Konder (2015, p. 59), vai contextualizar baseado nos estudos da obra de Marx que, ao longo de seu contexto histórico de relações em sociedade, homens e mulheres tomam e se utilizam de distintas formas de representar e transformar a realidade em que vivem, e se comportando de tal forma interpretam e encaram o mundo de maneiras particulares a seu contexto histórico. A este conjunto de modos particulares é que se constitui o complexo da ideologia. No entanto, o texto de Konder (2015, p. 59), nos chamou atenção a um questionamento do autor, "Enquanto o homem era menos humano do que propriamente animal, o que é que acontecia” (KONDER, 2015, p. 59)? Na tentativa de responder a tal questionamento, cremos ser necessário e importante ir até Lukács (2013, p. 478):

Com efeito, determinados momentos específicos da vida humana podem adquirir uma figura autônoma e, mediados dessa maneira, propiciar o fundamento para conceber o mundo analogicamente. Daremos destaque especial tão somente à categoria da teleologia - passando ao largo de exemplos importantes como vida, morte, perfeição, eternidade etc. A teleologia manteve-se até o século XIX, até Marx e Darwin, como categoria objetiva da natureza, embora não passasse de uma projeção analogizante do processo de trabalho sobre a natureza. A enumeração dessas deturpações de sentido poderia continuar indefinidamente, 
mas o que nos interessa aqui é apenas mostrar que muitos elementos da ideologia de algum modo já estavam presentes nos estágios mais iniciais do desenvolvimento social, que o surgimento dos antagonismos sociais, que passaram a ser enfrentados e resolvidos ideologicamente, não precisou criar um instrumento totalmente novo para dar conta da nova necessidade, mas encontrou um rico legado de meios para isso, que ela obviamente reelaborou de modo a corresponder às novas tarefas. Na realidade, todavia, essa situação é ainda mais inequívoca. Com efeito, até os achados arqueológicos, particularmente os feitos nos túmulos, mostram que até mesmo a sociedade ainda não subdividida em classes era forçada a levantar e a resolver problemas especificamente ideológicos (LUKÁCS, 2013, p. 478).

Sintetizando, de acordo com Lukács,o complexo categorial ideologia, já estava "presente" desde os primórdios da humanidade, claro que não da forma complexa com que se ela apresenta nas sociedades especificamente sociais, nossa assertiva se "comprova"na tese supracitada, a ideologia como complexo categorial do ser social assim como a reprodução e os estranhamentos têm sua gênese no trabalho, na atividade humano-sensível, ao nos referimos ao trabalho como gênese da ideologia em nada quer dizer que primeiro o trabalho, depois a reprodução, depois a ideologia, ou seja, mesmo que tenha sido a categoria fundante do ser social ele permanece indivorciável de toda atividade humana. Embora tenha realizado tal assertiva, Lukács (2013, p. 478), nos chama atençãopara um importante elemento, isto em nada deve vir a contrapor o fato de que as problemáticas que emergem no bojo da luta de classes "[...] sejam resultados de tempos posteriores, mas requer, ao mesmo tempo, que sua função social e, por isso, sua gênese e seu efeito sejam determinados de modo um pouco mais amplo" (LUKÁCS, 2013, p. 478).

Sustentados pelos escritos de Eagleton (1997), Konder (2002, 2015), Marx e Engels (2007), entendemos que, o complexo categorial da ideologia em Marx, advém de seus estudos sobre a alienação/estranhamento, que mais precisamente foi tratado nos Manuscritos Econômicos e Filosóficos(2004). Entendendo que a alienação/estranhamento está "relacionada" (mas não só) ao processo de reificação, explicitamente estudado por Lukács em História e Consciência de Classe (2003), na obra em destaque o filósofo húngaroapresenta suas reflexões sobre reificação ao dissertar sobre o fetichismo da mercadoria, presente nos escritos d'O Capital.Areificação para o filósofo húngaro vai atingir seu mais elevado grau de manifestação com o desenvolver das relações de troca nas relações mercantis de intercâmbio de mercadorias, e mais precisamente, com maior veemência na relação de troca entre a força de trabalho (única capaz de criar mais-valia) com o possuidor dos meios de produção. Ofenômeno da reificação irá aparecer também na teoria da pseudoconcreticidade de Karel Kosic (1976), no qual o ser toma a essência pelo fenômeno a mediação pelo imediatismo. No mundo da concentricidade em Kosic, a realidade social e as condições de existência do ser social, estão "subjugadas" aos ditames de uma falsa consciência, analisadas, pois, sob o prisma científico, ou seja, o positivismo.

Parece-nos, neste sentido, que existe uma tendência tanto em Lukács como em Kosic a uma "[...] superação das limitações filosóficas oficiais, como das duas correntes opostas que se aproximam do "Existencialismo e do Neopositivismo" (COSTA NETTO apud LIMA, 2011, p. 14). Neste sentido, ao escrever a sua grande ontologia, Lukács está relatando a sua apreensão do ser social e de seu movimento enquanto práxis humana, as formas de objetivação do ser social se situa em constante processo de transformação. Desta maneira, 
ao se "assumir" enquanto ser humano alienado/estranhado, frente as relações sociais capitalistas, o ser social não mais enxerga as mercadorias que produz, os fenômenos sociais enquanto oriundos de sua proporia atividade humano-sensível. Lukácsteve sua aproximação com os textos de Marx ainda em juventude, no entanto, é mais precisamente na Ontologia do Ser Social, no capítulo "O ideal e a ideologia" que ele vai se deter a estudar o complexo da ideologia. Conforme nos chama atenção Lessa (2015), emLukács a problemática de se referir a ideologia enquanto falsa consciência do real, não é senão defender que a ciência é uma instância neutra, no que diz respeito as relações, conflitos e mediações sociais, e sendo assim, ao adotar a ideologia apenas enquanto "falsa consciência", não estaríamos senão nos aproximando do método positivista de pensar as relações em sociedade.

\footnotetext{
Argumenta Lukács que a concepção da ideologia enquanto falsa consciência possui, ainda, outro ponto em comum com o positivismo: o critério para o julgamento do que seria ideologia e o que seria ciência estaria no conteúdo gnosiológico (um falso, outro verdadeiro). O fundamento da distinção entre ciência e ideologia seria procurado na determinação das condições de possibilidade de conhecimento do real. Não a função social, o papel efetivo que jogam na processualidade social, mas sim o conteúdo mais ou menos verdadeiro dos conhecimentos é que distinguiria ciência de ideologia (LESSA, 2015, p. 41).
}

No desenvolvimento dos escritos de sua grande obra,Lukács postula que o trabalho é a categoria fundante do ser social, é ele (o trabalho) quem permite a eterna e necessária relação do gênero humano com a natureza (transformação da natureza), o que o autor define como pôr teleológico primário (relação sujeito - objeto), ao passo que se desenvolve no e pelo trabalho o ser humano adquire capacidades de se relacionar uns com os outros, escolher entre alternativas, de incidir um sobre o outro, de acordo com o Lukács, pôr teleológicosecundário (relação sujeito - sujeito).Sem as posições teleológicas primárias, as secundárias se quer existiriam, portanto, é neste complexo das posições teleológicas secundárias que se situa o campo da ideologia (LESSA, 2015, p. 55). Ao se referir diretamente a Lukács, Lessa defende sua posição devido ao fato de que em Lukács:

\begin{abstract}
A ideologia é sobretudo a forma de elaboração ideal da realidade que serve para tornar a práxis social humana consciente e capaz de agir. Desse modo, surgem a necessidade e a universalidade de concepções para dar conta dos conflitos do ser social; nesse sentido, toda ideologia possui o seu ser-propriamente-assim social: ela tem sua origem imediata e necessariamente no hic et nunc social dos homens que agem socialmente em sociedade. Essa determinidade de todos os modos de exteriorização [Äußerungsweisen] humanos pelo hic et nunc do ser-propriamenteassim histórico-social de seu surgimento tem como consequência necessária que toda reação humana o seu meio ambiente socioeconômico, sob certas circunstâncias, pode se tornar ideologia (LUKÁCS, 2013, p. 465, grifos nossos).
\end{abstract}

Neste sentido, a ideologia é para o filosofo húngaro o hic et nunc de suas relações em sociedade em determinado tempo histórico, e são por meios destas relações que o ser social desenvolve capacidades subjetivas e objetivas de oferecer respostas a eles demandadas.E na medida em que as relações em sociedade se complexificam cada vez mais, exige também dos indivíduos posições teleológicas cada vez mais complexas, e sendo assim, imputa em duas consequências significativas para a compreensão da ideologia (LESSA, 2015, p. 43), Lessa (2015, p. 42-43), sustenta sintéticamente tais consequências: 
Em primeiro lugar, dão origem a complexos sociais específicos que têm a função de regular a práxis social de modo a tornar possível ('operativa') a reprodução da sociedade. Pensemos, como exemplo, no direito. A complexificação social e o surgimento das classes terminam por dar origem a um complexo social particular com uma função específica: regular juridicamente os conflitos sociais tornados antagônicos. [...].

A segunda consequência advinda do desenvolvimento da sociabilidade é a crescente necessidade de respostas genéricas que permitam ao indivíduo não apenas compreender o mundo em que vive, mas também justificar a sua práxis cotidiana, tornando-a aceitável, natural, desejável. Essa função de fornecer tais respostas genéricas, repetimos, cabe à ideologia (LESSA, 2015, p. 42-43).

Assim podemos dizer que, a ideologia é, um complexo da vida social, fundada no trabalho - modelo da práxis humana - e sendo assim, a ideologia, possui uma função social em específico, "explicar" as relações em sociedade, interesses individuais e/ou coletivos que podem ou não, serem antagônicos, o que a grosso modo, propiciam o surgimento de ideologias. Neste sentido, de acordo com Lessa (2015, p. 45), o que faz uma ideação tornarse uma ideologia, é sua capacidade de dar sentido às demandas postas pelas relações sociais em determinado contexto histórico. Lessa (2015) continua suas argumentações e nos explicita que, pensar a ideologia enquanto função social operante e não enquanto falsa consciência ou "o fato de Lukácsbuscar a função social da ideologia e não um critério gnosiológico na sua caracterização", nãoé para levar-nos a determinar "maior ou menor veracidade de uma ideologia", pelo contrário, é para que apreendamos a ideologia também enquanto um complexo da vida social que, possui uma função social, como já afirmado. Determinar a maior ou menor verdade de uma ideologia não é o ponto principal dos escritos de Lukács, uma vez que, a verdade não pode ser medida ou provada, é necessário que a entendamos enquanto o contínuo processo de conhecimento (SCHAFF, 1995), enquanto seres sociais inseridos em relações sociais históricas e mutáveis. Lukács (2013, p. 467-8; p. 480-1), sustenta os pressupostos acima levantados:

Porém, verdade ou falsidade ainda não fazem de um ponto de vista uma ideologia. Nem um ponto de vista individualmente verdadeiro ou falso, nem uma hipótese, teoria etc., científica verdadeira ou falsa constituem em si e por si só uma ideologia: eles podem vir a tornar-se uma ideologia, como vimos. Eles podem se converter em ideologia só depois que tiverem se transformado em veículo teórico ou prático para enfrentar e resolver conflitos sociais, sejam estes de maior ou menor amplitude, determinantes dos destinos do mundo ou episódicos. Não é difícil perceber isso no plano histórico. A astronomia heliocêntrica ou a teoria do desenvolvimento no âmbito da vida orgânica são teorias científicas, podem ser verdadeiras ou falsas, mas nem elas próprias nem a sua afirmação ou negação constituem uma ideologia. Só quando, depois da atuação de Galileu ou Darwin, os posicionamentos relativos às suas concepções se converteram em meios para travar os combates em torno dos antagonismos sociais, elas se tornaram operantes - nesse contexto - como ideologias. A conexão de sua verdade ou falsidade com essa função de ideologia naturalmente desempenha um papel importante, inclusive ideológico, na análise concreta da respectiva situação concreta, mas, enquanto o tema for as controvérsias sociais, isso não muda nada no fato de que devem ser consideradas como ideologias (ou, pelo menos, também como ideologias). Nem uma reversão da função de cunho progressista para a de cunho reacionário altera qualquer coisa nesse status social da ideologia; os adeptos liberais de Herbert Spencer transformaram o darwinismo em ideologia do mesmo modo que fez o séquito reacionário do 'darwinismo social' no período imperialista. 
Diante deste contexto, concordamos com Lessa (2015, p.46), sustentado pelas análises lukacsianas: "Em suma, o fenômeno da ideologia corresponde a uma necessidade social concreta: a cada momento as sociedades necessitam ordenar a práxis coletiva dentro de parâmetros compatíveis com a sua reprodução".E ao defender tal posição, Lukács vai explicitar que existem formas específicas de ideologia (arte e filosofia) que não intervém imediatamente nos movimentos sociais, estas possuem o gênero humano como "objeto" de estudo. No que se refere a arte, Lukács diz que esta é o campo de evasão da subjetividade humana o campo da desfetichização do ser social, é através dela que o homem/mulher cria o não existente, ela é "Ontologicamente, ela é o elo de mediação entre o homem meramente particular e o homem que almeja ser, de modo inseparável, simultaneamente individualidade e ser genérico". (LUKÁCS, 2013, p. 546). Já em relação a filosofia, que para Lukács (2013, p. 540), “ [...] aprofunda as generalizações das ciências, antes de tudo, por estabelecer uma relação inseparável com o nascimento histórico e o destino do gênero humano, com a essência, o ser e o devir humanos". Neste sentido, a filosofia para Lukács, está mais próxima da ciência e são indispensáveis para a reprodução do ser social, não obstante a filosofia questiona o indivíduo, o de onde? Para onde? Quais as origens do mundo? E do próprio ser? Entre outras indagações. Nas palavras do autor:

\footnotetext{
O desenvolvimento da humanidade de fato produziu tais ideologias, sobretudo na filosofia e na arte. Estas são as formas mais puras da ideologia, na medida em que elas não têm a intenção nem a capacidade de exercer qualquer tipo de impacto imediato e real sobre a economia nem sobre as formações sociais a ela associadas, indispensáveis à sua reprodução social, sendo, contudo, insubstituíveis no que se refere à solução real dos problemas aqui propostos (LUKÁCS, 2013, p. 538).
}

Assim como arte e filosofia são formas puras de ideologia, o filosofo húngaro diz que o direito e a política são formas específicas de ideologia. De acordo com Vaisman (2014, p. 101), o direito nasce a partir da necessidade de resolver e ordenar os conflitos gerados a partir da organização do processo de trabalho e derivados do processo produtivo, a origem do direito se dá ao passo que a divisão social do trabalho se complexifica e se diferencia ao longo do processo histórico das contradições geradas entre capital e trabalho, e ao passo que se complexifica, este complexo vai se tornando cada vez mais específico.Em relação ao complexo do direito, Hillesheim (2015) explica que o direito mascara a essência do fenômeno, sua função social constitui-se numa ideologia cujo objetivo é o de alcançar a sujeição de homens e mulheres àestrutura econômica vigente, e em consequência, o encobrimento da luta de classes. Neste sentido, é a partir da perspectiva de totalidade que se pode compreender o direito como ideologia, ou seja, na medida em que o ser social busca respostas a necessidades que se coloca frente ao processo econômico-social, ele orienta sua práxis de tal forma que dessa orientação possa determinar sistemas ideológicos ou mais precisamente, formas específicas de ideologia.No que se refere a política, Vaisman(2014, p. 106) analisaque a práxis política é a forma pela qual são conscientizados e enfrentados os conflitos que concernem à sociedade como um todo. $\mathrm{E}$ por se referir ao contexto social, a política é uma posição teleológica na qual modifica todo um contexto fenomênico de mundo, na qual busca alternativas tanto para a modificação das estruturas sociais, bem como a transformação da sua própria essência. De acordo com Lukács (2013, p. 502), não existe uma sociedade se quer, em nenhum canto, por menor que seja, que não coexistam com questões políticas. Diante deste contexto, o autor nos esclarece: 
A política é uma práxis que, em última análise, está direcionada para a totalidade da sociedade, contudo, de tal maneira que ela põe em marcha de modo imediato o mundo fenomênico social como terreno do ato de mudar, isto é, de conservar ou destruir o existente em cada caso; contudo, a práxis desencadeada desse modo inevitavelmente é acionada de modo mediado também pela essência e visa, de modo igualmente mediado, também à essência. A unidade contraditória de essência e fenômeno na sociedade ganha na práxis política uma figura explícita (LUKÁCS, 2013, p. 502).

Tem-se aqui a sustentação ontológica da ideologia (LESSA, 2015, p. 137), por ter se fundado no e a partir do trabalho, a ideologia enquanto posição teleológica secundária tem seu fundamento na transformação das relações entre os seres humanos que vivem em sociedade. E por assumir o caráter de função social operante nas relações sociais entre homens, o complexo da ideologia está fadado ao conflito de interesses e, não obstante, rodeada de alternativas válidas ou não, cabe ao ser social discernir entre quais alternativas seguir, neste sentido a escolha entre alternativas está intrinsecamente relacionada a ações teleologicamente objetivadas e as causalidades naturais, e nesta relação dialética quer queiramos ou não, ocorrerão causalidades. De acordo com Lessa (2015, p. 137), defender a ideologia enquanto função social em detrimento de falsa consciência do real permitea Lukács superar a neutralidade científica, defendida pelos positivistas. Realizado este movimento de analisar o complexo da ideologia em sua perspectiva categorial, passemos agora a analisaro complexo da ideologia no Serviço Social, destaca-se neste tema no interior do Serviço Socialos estudos de lamamoto, Netto, Costa, Tavares, Faleiros, como já mencionamos anteriormente, é sob os estudos dos/das autores/autoras supracitados que sustentaremos a análiseque segue.

\section{O COMPLEXo da IDEOLOGia E O SERVIÇo SOCIAL: UM DEbate NECESSÁRIo PARA A SUSTENTAÇÃo do PROJETO ÉTICO-POLÍTICO PROFISSIONAL}

Nos escritos de lamamoto (1985) está evidenciado que o Serviço Social é uma profissão que se estabelece a intervir junto aos interesses das classes que dão vida a sociedade capitalista (classe trabalhadora), a profissão do/da assistente social ao se afirmar enquanto uma especialização do trabalho coletivo tem sua intervenção sustentada nas contradições oriundas da relação capital $x$ trabalho, ou mais precisamente de acordo com a autora, no enfrentamento da "questão social". A autora define assim a "questão social":

A questão social não é se não as expressões do processo de formação e desenvolvimento da classe operária e seu ingresso no cenário político da sociedade, exigindo o seu reconhecimento como classe por parte do empresariado e do Estado. É a manifestação, no cotidiano da vida social, da contradição entre o proletariado e a burguesia, a qual passa a exigir outros tipos de intervenção, mais além da caridade e repressão. $O$ Estado passa a intervir diretamente nas relações entre o empresariado e a classe trabalhadora, estabelecendo não só uma regulamentação jurídica do mercado de trabalho, através da legislação social e trabalhista específicas, mas gerindo a organização e prestação de serviços sociais, como um novo tipo de enfrentamento da questão social. (IAMAMOTO, 2007, p. 168).

Ainda nos escritos de lamamoto (2007), o trabalho profissional tem seu significado a partir das relações que desenvolve com os sujeitos sociais que demandam seus serviços. "O significado social de seu processamento não é idêntico nas diferenciadas condições em que 


\section{tempordilis}

NUNES, LEANDRO; JUSTINO, ALINE APARECIDA

realiza esse trabalho porquanto envolvido em relações sociais distintas". (IAMAMOTO, 2007. p. 215). O empregadorseja ele público ou privado, é quem "define" a que demandas o profissional terá de intervir, mesmo que o/a profissional queira atender as demandas mais emergentes ou a outras demandas que surjam no desenvolver de sua ação profissional, ainda esbarra nos trâmites burocráticos do Estado, falta de recursos, processo de contrarreformas nas políticas sociais, entre outros, tais ditames interferem cada vez com maior veemência no fazer profissional destes/destas profissionais.Assim, a ação profissional sob os nortes institucionais torna-se mais uma convergência das classes demandatárias a um dito acesso as necessidades básicas de reprodução de sua vida, do que realmente uma intervenção profissional para além do acesso aos direitos. Nas palavras de lamamoto (2007, p. 218),por estarem nacondição de assalariado, a/o assistente social:

[...] seja como funcionário público ou assalariado de empregos privados, empresariais ou não - envolve, necessariamente, a incorporação de parâmetros institucionais e trabalhistas que regulam as relações de trabalho, consubstanciadas no contrato de trabalho, que estabelecem as condições em que esse trabalho se realiza: intensidade, jornada, salário, controle do trabalho, índices de produtividade e metas a serem cumpridas (IAMAMOTO, 2007, p. 218).

Em Relações Sociais e Serviço Social no Brasil: esboço de uma interpretação históricometodológica, lamamoto e Carvalho (1985), destinam dois itens em específico ao estudo da estrutura político-ideológica da profissão, o primeiro se refere ao Serviço Social e reprodução do controle da ideologia dominante e um segundo intitulado como expansão da profissão e ideologia dominante, analisemos brevemente cada um deles. Quanto ao primeiro Serviço Social e reprodução do controle da ideologia dominante, lamamoto e Carvalho relatam que algumas considerações devem ser dignas de estudo. O controle social e a difusão da ideologia dominante se expressam enquanto recursos essenciais para a manipulação e obtenção do consenso das classes dominadas socialmente, tendo assim de se adequar a ordem societária em curso. No entanto, é necessário que se explicite: várias são as ideologias e formas de ver o mundo, e tais convivem, reproduzem-se e se confrontam entre si. (IAMAMOTO; CARVALHO, 1985, p. 109). Iamamoto\& Carvalho (1985, p. 111), nos chamam a atenção: mesmo que se ressalte que a ideologia seja portadora de tamanha força, a eficácia desta ainda se mostra de maneira limitada, "se encobre as contradições na e para a consciência, não as elimina". Após realizar uma análise concisa e didática da reprodução da ideologia dominante e suas referidas influências na ação profissional do/da assistente social, lamamoto e Carvalho (1985, p. 117), chegam à seguinte conclusão:

Sendo o assistente social um técnico em relações humanas por excelência, essas características apontadas na prática profissional são recuperadas pelos representantes do poder no sentido de interferência e controle de aspectos da vida cotidiana da classe trabalhadora, utilizando-se da mediação desse intelectual. [...]. Essa ação controladora, no entanto, é esvanecida pelo discurso humanista e humanizador acoplado a esse tipo de intervenção, discurso esse mobilizado e incorporado pela própria burguesia e, ao mesmo tempo, sabotado na prática pela subordinação da atividade profissional a um projeto de classe (IAMAMOTO, 1985, p. 117).

Em outro subitem intitulado expansão da profissão e a ideologia desenvolvimentista, a autora vai definir desenvolvimentismo como o período em que se buscou a expansão econômica através de medidas continuadas e autossustentadas, era necessário para a 
ideologia dominante manter um ambiente de paz política, social e de segurança, assim, a ideologia desenvolvimentista definir-se-á a partir do momento em que "[...] todo o esforço de elaboração política e trabalho são requeridos para eliminar o pauperismo, a miséria, elevando-se o nível de vida do povo como consequência do crescimento econômico atingido". (IAMAMOTO; CARVALHO, 1985, p. 347). Neste contexto:

O Serviço Social se interioriza, acompanhando o caminho das grandes instituições, a modernização das administrações municipais, e o surgimento de novos programas voltados para as populações rurais. Ao mesmo tempo, nas instituições assistências - médicas, educacionais, etc. - o Serviço Social paulatinamente logra de maior sistematização técnica e teórica de suas funções, alcançando definir áreas preferenciais de atuação técnica (IAMAMOTO; CARVALHO, 1985, p. 350).

No decorrer do processo histórico brasileiro a profissão se institucionaliza no âmbito da implementação das políticas sociais, sejam elas públicas ou privadas, e tais políticas se configuram enquanto formas instrumentalizadas de controle social, elas é quem imprimem a conduta com que os seres humanos devem se adequar "[...] aos padrões legitimados de vida social, manipulando racionalmente os problemas sociais, prevenindo e canalizando a eclosão de tensões para os canais institucionalizados estabelecidos oficialmente" (IAMAMOTO; CARVALHO, 1985, p. 111). "Longe" de estarmos envolvidos desde o período de planejamento das políticas sociais ainda somos "[...] agentes executores das políticas sociais [...]" como nos lembra Netto (1992, p. 74), ou seja, o/a assistente social exerce sua profissão diretamente junto à população demandatária, ao "viabilizar" o seu acesso aos direitos.

José Paulo Netto (1992) em Capitalismo Monopolista e Serviço Social vem a ser outra referência de peso ao analisar a dimensão ideo-política da profissão. Ao desenvolver seus escritos, Netto defende a tese de que estrutura social da profissão é sincrética: “[...] o sincretismo nos parece ser o fio condutor da afirmação e do desenvolvimento do Serviço Social como profissão, seu núcleo organizativo e sua norma de atuação" (NETTO, 1992, p. 92). Ao se referir ainda sobre a tese do sincretismo Netto (1992, p. 92) explicita que três são os fundamentos objetivos da estrutura sincrética do Serviço Social: "[...] o universo problemático original que se lhe apresentou como eixo de demandas histórico-sociais, o horizonte do seu exercício profissional e sua modalidade específica de intervenção" (NETTO, 1992, p. 92). Mais à frente, Netto (1992, p. 108) vai deixar claro que a o sincretismo ideológico acompanhou toda evolução histórica do Serviço Social, desde "[...] suas protoformas aos seus estágios profissionalizados mais desenvolvidos e especializados" (NETTO, 1992, p. 108). De acordo com lamamoto (2007):

Após caracterizar o sincretismo no Serviço Social nos termos antes assinalados, Netto (1992) desdobra-o nos níveis da 'prática indiferenciada', do 'sincretismo científico' e do 'sincretismo ideológico'. O acervo da produção especializada, que tem na profissão o objeto central de reflexão, as análises de Netto (1992) acerca do 'sincretismo ideológico' - focando a trajetória da influência conservadora europeia e norte-americana na cultura profissional - e acerca do 'sincretismo científico' - abordando o embate teórico-metodológico entre as ciências sociais e a teoria social - são, sem sombra de dúvidas. As mais ricas e consistentes, que nos foram legadas nas últimas décadas (IAMAMOTO, 2007, p. 273). 


\section{tempordilis}

Em sua dissertação de mestrado intitulada Trabalho e Serviço Social: debate sobre a concepção de Serviço Socialcomo processo de trabalho com base na Ontologia de Georg Lukács, Gilmaísa Costa (1999), entra no debate do complexo da ideologia e Serviço Social. A autoria vai enfatizarque a ação profissional do/da assistente social possui uma materialidade distinta de outros profissionais, uma vez que sua intervenção incide sobre um elemento social e não natural, neste sentido a mesma retorna ao núcleo de fundamentos da formação profissional, e que o "objeto" da ação profissional, os problemas e respostas que se apresentam a este profissional emergem no interior das relações em sociedade. Costa (1999) sustentada pelos escritos de Sergio Lessa defende a tese de que o Serviço Social deve ser entendido enquanto posição teleológica secundária, pois o "resultado" fim de seu processo de trabalho não cria uma mercadoria que podemos manipular, tocar, etc., ou seja, a ação profissional do/da assistente social não transforma a natureza. A autora sustenta seus argumentos a partir da seguinte análise:

Com essas considerações, buscamos evidenciar que o fato de uma profissão constituir-se numa especialização originada na divisão social do trabalho não implica sua caracterização como trabalho. O Serviço Social certamente é uma profissão que deriva da divisão-sócio técnica do trabalho; as necessidades sóciohistóricas que o legitimam como profissão o vinculam a um fenômeno típico da fase capitalista dos monopólios. Entretanto, isso não significa que, com sua atividade frente a determinadas realidades sociais, se realize um processo de trabalho no preciso sentido do termo (COSTA, 1999, p. 89).

Na esteira de seus argumentos Costa (1999) irá defender que o Serviço Socialnão é trabalho, mas o que seria então Serviço Socialpara Costa?Vejamos a seguinte passagem de sua dissertação:

Assim, se o Serviço Social nasce como uma resposta voltada a combater conflitos sociais e, se é nesta tensão entre produção da desigualdade e produção da rebeldia e da resistência, que trabalham os assistentes sociais, situados nesse terreno movido por interesses distintos, conforme afirma Marilda lamamoto [...], o Serviço Social encontra-se dentro dos critérios como veículo prático da ideologia.

Estamos falando de um veículo prático porque, como sabemos através da recuperação histórica da profissão, o Serviço Social não surge na sociedade capitalista com a tarefa de produzir conhecimentos, mas como uma prática social inserida institucionalmente e predominantemente exercida junto a indivíduos ou a famílias consideradas carente de ajuda material ou moral (COSTA, 1999, p. 9798).

Diante de tais argumentos, ao situar o trabalho profissional no âmbito das relações em sociedade, Costa (1999) define o Serviço Socialenquanto manifestação da ideologia, em suas sustentações a autora assevera que:

Numa primeira aproximação à problemática do Serviço Social como ideologia, o vínculo entre o Serviço Social e a questão social conduz a uma identificação desta profissão como uma ação voltada à resolução de conflitos de interesses entre os homens, que se expressam no cotidiano mais imediato.

Além disso, o aparecimento dessa profissão determinado pela complexificação de produção material e pela acentuação da divisão social do trabalho na formação social capitalista, vinculada à ações do Estado, são indícios muito fortes na caracterização do Serviço Social como complexo ideológico restrito. Entretanto, 
isso merece um tratamento cuidadoso para não incorremos em conclusões precipitadas (COSTA, 1999, p. 103).

Nota-se na passagem acima um polêmico debate, a nosso entendimento, o de, "situar" o Serviço Socialenquanto ideologia restrita. Em Costa (1999, p. 104), o campo dos complexos ideológicos restritos se situa na "barreira" entre as atividades econômicas e os mais variados interesses que emergem no seio da sociedade de classes,este vem a ser o motivo de Costa (1999) situar o Serviço Socialenquanto ideologia, uma vez que sua ação profissional se direciona a responder as demandas que emergem no bojo da relação entre capital e trabalho. Por fim Costa (1999, p. 108-109), sintetiza que:

\begin{abstract}
A análise da concepção de Serviço Social com base no pensamento de Georg Lukács levou-nos à apreensão do Serviço Social como complexo ideológico do ser social, decorrente de sua função nos conflitos sociais. Por outro lado, um complexo onde as generalizações produzidas pela categoria situam-se entre a ideologia restrita, no sentido de se dirigirem aos conflitos mais imediatos da vida social e a ideologia pura como momento ideal que se refere aos problemas do gênero humano. Deste modo, damos por conclusivo que, na Concepção de Serviço Social como trabalho, exposta no Núcleo de fundamentos do trabalho profissional, existe uma imprecisão teórica que conduz à confusão entre as formas ontologicamente diferentes de práxis sociais. O trabalho, no qual o sujeito interage com a objetividade natural e as posições teleológicas secundárias, onde o sujeito tem como mediação da práxis humana a consciência dos indivíduos com vistas ao desenvolvimento dos processos sociais. Na perspectiva que aqui defendemos, a atividade profissional do Serviço Social não se constitui processo de trabalho no sentido estrito, a base ontológica do Serviço Social é a ideologia, como atividade que exerce uma função nos conflitosa sociais (COSTA, 1999, p. 108-109).
\end{abstract}

O processo de reestruturação produtiva ocorrido entre os anos de 1970/1980 não rebateram apenas sobre a organização do trabalho, mas também no Estado, implicando deste modo numa "nova" concepção de política, a política neoliberal. O Estado, sob este viés político "se torna" burocrático, ineficiente e ineficaz em suas ações de intervenção e regulação da sociedade. Tem-se neste contexto a evocação do setor privado como único possuidor de uma racionalidade capaz de proporcionar o crescimento econômico, obedecendo as normas impostas pela política em comento do "livre mercado". No campo da política, o ideal neoliberal induz a hegemonia e poder da burguesia ao reduzir a participação dos demais setores da sociedade a uma "mera" participação nos processos eleitorais burgueses, tem-se neste contexto uma redução da concepção de democracia, a "liberdade" de todas e todos os cidadãos e cidadãs de votar e ser votado. Outro grande discurso que está na ordem do dia desde então, principalmente na atualidade brasileira, pós aprovação da PEC $55^{2}$, é a chamada necessidade de cortes nos gastos públicos sob a justificativa da crise fiscal do Estado. Para Soares (2002, p. 34), "O ajuste neoliberal deve ser entendido não apenas como medidas de caráter exclusivamente econômico, mas também como um projeto global para a sociedade - com políticas articuladas em todos os âmbitos, inclusive o social" (SOARES, 2002, p. 34). Deste modo, joga-se a culpa de tal crise

\footnotetext{
${ }^{2}$ De acordo com matéria veiculada pela Carta Capital no dia 31/11/2016, a proposta limitará gastos drásticos no setor público nos próximos 20 anos e o efeito mais drástico "[...] será uma redução significativa nos gastos com educação e saúde, os únicos da proposta que exigem uma mudança da Constituição. Haverá grande impacto sobre a parcela mais pobre da população e estímulo aos negócios privados nas duas áreas" (ENTENDA..., 2016).
} 
sob a proteção social, ou mais precisamente, sobre o Estado de bem-estar social (WelfareState) que nos países latino-americanos nunca veio a existir. Porém como é sabido, este discurso não é senão uma forma de diminuir os gastos do Estado com as políticas sociais e favorecer o crescimento do setor privado nos setores da educação, saúde, previdência, habitação, transporte, etc.Em termos gerais, engendra-se um discurso onde a culpa pelo "fracasso" da situação em que se vive é única e exclusiva do indivíduo, e é ele quem deve buscar os caminhos para tal superação, não importando os meios, e como podemos perceber os meios a serem ofertados se encontram no setor privado. Nas palavras de Soares (2002, p. 40), cabe lembrar que:

\footnotetext{
Um dos componentes ideológicos por trás desse tipo de proposta é a ideia de que o setor público caracteriza-se, por princípio, em qualquer circunstância, como ineficiente e ineficaz, ao contrário do setor privado, o único a possuir uma 'racionalidade' e uma 'vocação' capazes de levar ao crescimento econômico. As possibilidades de sucesso da proposta privatizante estariam assim garantidas desde que o Estado não interferisse (SOARES, 2002, p. 40).
}

Neste sentido, em tempos de privatização das políticas sociais, há uma tendência das ações profissionais do/da assistente social de se tornarem imediatistas e despolitizadas, caminhando para uma forma de assitencialização da pobreza.Por fim, concordamos com Netto (2015, p. 168) quando analisa que:

\begin{abstract}
Panoramicamente, o Serviço Social com que se depara o observador contemporâneo configura-se como um caleidoscópio de propostas teóricometodológicas, com marcadas fraturas ideológicas, projetos profissionais em confronto, concepções interventivas diversas, práticas múltiplas, proposições de formação alternativas - sobre o patamar de uma categoria profissional com formas de uma categoria profissional com formas de organização antes desconhecidas e o pano de fundo de uma discussão teórica e ideológica ponderável também inédita (NETTO, 2015, p. 168).
\end{abstract}

\title{
CONSIDERAÇÕES FINAIS
}

Acreditamos que no meio de tantas adversidades os princípios e deveres contidos em nosso Código de Ética de 1993 e Lei de Regulamentaçãoda Profissão devem ser observados e defendidos, bem como a direção profissional do nossoprojeto ético-político profissional na qual nos indica caminhos ao exercício da profissão sob o prisma da teoria social crítica, com vistas não só a universalização do acesso aos direitos, mas também na construção de outro projeto de sociedade, onde a emancipação humanaestáno horizonte. O complexo da ideologia sob nortes neoliberais não mais se assume enquanto função social, mas sim, enquanto falsa consciência do real.

Estamos convencidos de que os/as assistentes sociais enquanto classe trabalhadora e em conjunto com os demais setores oprimidos da sociedade devem atuar na luta contra quaisquer formas de regressão nos direitos sociais e políticos."Nenhum direito a menos! Essa luta é nossa, é da classe trabalhadora!"3 (CONSELHO FEDERAL DE SERVIÇO SOCIAL, 2015). É o grito que deve evocar e ganhar as ruas nesses tempos tempestuosos de governo neoliberal e golpista, que a cada novo raiar de sol busca retiraros direitos sociais a muito

\footnotetext{
${ }^{3}$ Campanha difundida pela gestão do CFESS 2014/2017 Tecendo a luta a manhã desejada.
} 


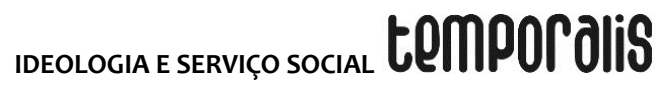

conquistados pelas mãos descarnadas de um povo que, mesmo com todas as dificuldades, jamais ousou se retrair na luta pela conquista de direitos.

\section{REFERÊNCIAS}

CONSELHO FEDERAL DE SERVIÇO SOCIAL. Vamos de mãos dadas para 2016. Brasília (DF), 29 dez. 2015. Disponível em: <http://www.cfess.org.br/visualizar/noticia/cod/1236>. Acesso em: 15 fev. 2017. EAGLETON, T. Ideologia. Uma introdução/Terry Eagleton; tradução Silvana Vieira, Luís Carlos Borges. São Paulo: Editora da Universidade Estadual Paulista: Editora Boitempo, 1997.

ENTENDA o que está em jogo com a aprovação da PEC 55. Carta Capital, 30 nov. 2016. Disponível em: <https://www.cartacapital.com.br/economia/entenda-o-que-esta-em-jogocom-a-aprovacao-da-pec-55>. Acesso em: 15 fev. 2017.

IAMAMOTO, V. Serviço Social em tempo de capital fetiche. São Paulo: Cortez, 2007.

IAMAMOTO, V.; CARVALHO, R. Relações sociais e Serviço Social no Brasil: esboço de uma interpretação histórico-metodológica. 8. ed. São Paulo: Cortez, 1985.

HILLESHEIM, J. Conciliação trabalhista: ofensiva sobre os direitos dos trabalhadores na periferia do capitalismo. 2015, 693 p. Tese (Doutorado em Serviço Social)-Universidade Federal de Santa Catarina - Programa de Pós-Graduação em Serviço Social, Florianópolis, 2015.

KONDER, L. Marx: vida e obra. 3. ed. -São Paulo: Expressão Popular, 2015.

KONDER, L. A questão da ideologia. São Paulo: Companhia das letras, 2002.

KOSIK, Karel. Dialetica do concreto. 2. ed. Rio de Janeiro: Paz e Terra, 1976. 230p.

LESSA, S. Para compreender a ontologia de Lukács. 4. ed. São Paulo: Instituto Lukács, 2015.

LUKÁCS, G. Para uma ontologia do ser social II. Tradução: Nélio Schneider, Ivo Tonet, Ronaldo Vielmi Fortes. São Paulo: Boitempo, 2013.

NETTO, J. P. Ditadura e Serviço Social: uma análise do Serviço Social no Brasil pós-64. 17. ed. São Paulo: Cortez, 2015.

NETTO, J. P. Transformações societárias e Serviço Social: notas para uma análise prospectiva da profissão no Brasil. Serviço Social \& Sociedade, São Paulo, ano 17, n. 50, p. 87-132, abr. 1996.

NETTO, J. P. Capitalismo monopolista e Serviço Social. 6. ed. São Paulo: Cortez, 1992. 


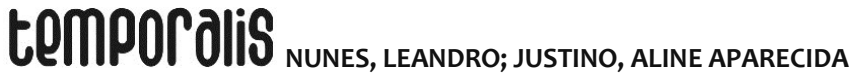

MARX, Karl; ENGELS, Friedrich. A ideologia alemã: critica da mais recente filosofia alemã em seus representantes Feuerbach, B. Bauer, Stirner, e do socialismo alemão em seus diferentes profetas, 1845-1846. São Paulo: Boitempo, 2007. 614 p.

SCHAFF, Adam. Historia e verdade. 6. ed. São Paulo: M. Fontes, 1995. 317p.

SOARES, L. T. Os custos do ajuste neoliberal na América Latina. 2 ed. São Paulo: Cortez, 2002 (Col. Questões da nossa época; v. 78).

VAISMAN. E. A ideologia e sua determinação ontológica. In: ALCANTÂRA, N.; COSTA, G. (Org.). Anuário Lukács 2014. São Paulo: Instituto Lukács, 2014. 